\title{
Reduction of Natural Organic Matter and Disinfection By-Product Precursors by Coagulation and Adsorption
}

\author{
E.-E. Chang ${ }^{1}$; Pen-Chi Chiang ${ }^{2}$; Su-Huei $\mathrm{Chao}^{3}$; and Chung-Huei Liang ${ }^{4}$
}

\begin{abstract}
Source water from King-Men Reservoir water in Taiwan was treated by alum and polyaluminum chloride coagulation, and the corresponding natural organic matter was fractionated by ultrafiltration membranes for determining its molecular weight (MW) distribution to provide the baseline information for further investigation. Due to the characteristics of the source-water nature, a lower alum dosage could reduce the total organic carbon (TOC) concentration by a great amount (25\%), while the difference in TOC removal efficiency was found to be insignificant at a higher dosage $(60-90 \mathrm{mg} / \mathrm{L})$ and even operating in a lower $\mathrm{pH}$ range. The results show that the larger MW coagulant polyaluminum chloride, having higher-charge neutralization and bridging capacities, exhibits better performance than the lower MW alum. In addition, the granular-activated carbon-adsorption process provides a relatively lower THMFP in the treated water at the same level of trihalomethanes and to lower the coagulant doses demand as well.
\end{abstract}

DOI: 10.1061/(ASCE)1090-025X(2004)8:1(57)

CE Database subject headings: Coagulation; Adsorption; Abatement and removal; Taiwan; Organic matter; Water treatment.

\section{Introduction}

Natural organic matter (NOM) is a term used to describe the complex matrix of organic material present in natural waters, and A relationship exists between its characteristics and treatabilities (Owen et al. 1995). Molecular weight (MW) distribution of NOM is one of the important parameters in characterizing NOM (Amy et al. 1992; Newcombe et al. 1997). In water-treatment processes, each unit process may exhibit different removal efficiencies for a specific MW fraction of NOM (Jacangelo et al. 1995). For example, some investigators have suggested that coagulation is suitable to treat a higher MW fraction of NOM.

In addition, ultraviolet (UV) absorption, a useful surrogate measurement of selected organic constituents in fresh water, may exhibit strong correlation with organic-carbon content, color, and precursors of disinfection by-product (DBP). (Najm 1994). Furthermore, our previous studies found that the parameters including the nature of NOM, chlorine dosage (or demand), UV absorbance, and total organic carbon (TOC) should be used to estimate the DBP formation potential (DBPFP) (Chang et al. 2001a,b) and found that there was no reduction of $\mathrm{UV}_{254}$ dissolved organic carbon (DOC) in the coagulation, filtration, and granularactivated carbon (GAC) for the preozonation processes; in fact

\footnotetext{
${ }^{1}$ Professor, Dept. of Biochemistry, Taipei Medical Univ., $250 \mathrm{Wu}$-shin St., Taipei 110, Taiwan.

${ }^{2}$ Professor, Graduate Institute of Environmental Engrg., National Taiwan Univ., 71 Chou-shan Rd., Taipei 106, Taiwan.

${ }^{3}$ Student, Dept. of Biochemistry, Taipei Medical Univ., $250 \mathrm{Wu}$-shin St., Taipei 110, Taiwan.

${ }^{4}$ Student, Graduate Institute of Environmental Engineering, National Taiwan Univ., 71 Chou-shan Rd., Taipei 106, Taiwan.

Note. Discussion open until July 1, 2004. Separate discussions must be submitted for individual papers. To extend the closing date by one month, a written request must be filed with the ASCE Managing Editor. The manuscript for this paper was submitted for review and possible publication on October 18, 2002; approved on September 26, 2003. This paper is part of the Practice Periodical of Hazardous, Toxic, and Radioactive Waste Management, Vol. 8, No. 1, January 1, 2004. (OASCE, ISSN 1090-025X/2004/1-57-64/\$18.00.
}

the $\mathrm{UV}_{254} / \mathrm{DOC}$ increases after the GAC process. This evidence strongly suggests that both pre and postozonation can effectively lower the $\mathrm{UV}_{254}$ /DOC values, thus reducing the DBPFP through converting precursors to nonprecursors (Chiang et al. 2002). TOC is a more convenient and direct expression of TOC and can be used to evaluate the effects of DBP control strategies. Singer (1994) suggested that chlorine consumption was a reasonably good indicator of DBP formation. Edzwald et al. (1985) and Najm et al. (2000) reported that the DOC rather than TOC is a more appropriate indicator of DBPFP in water-treatment plants.

The reduction of NOM by various methods including coagulation, oxidation, adsorption, and membrane filtration has been revealed in several studies (Semmens and Field 1980; Chadik and Amy 1983; Reckhow and Singer 1984; Hubel and Edzwald 1987; Krasner and Amy 1995). Kavanaugh (1978) and Babcock and Singer (1979) demonstrated that coagulation with alum and ferric salts was effective in removing turbidity and reducing organic DBP precursors. In the coagulation process, the effects of high dosage up to the overdose range are readily apparent because of the formation of hydrolyzed species. Edzwald (1993) found a better DOC removal by coagulants in water with higher specific UV absorbance. The U.S. EPA's 1998 Stage 1 disinfection byproduct rule (DBPR) provides an NOM removal strategy called enhanced coagulation to limit the formation of DBP. TOC removal requirements based on the TOC-alkalinity matrix on source-water characteristics are shown in Table 1 (U.S. EPA 1998). White et al. (1997) reported that water sources with high TOC and low alkalinity would need the proposed Step 1 TOC requirements, while those source waters with low TOC were required to employ the alternative process to meet the drinkingwater standards. The benefit to using this enhanced coagulation practice is to avoid forcing a unit to introduce a high dosage of coagulants to reduce the $\mathrm{pH}$ to between 5 and 6 , which is, in general, the optimal $\mathrm{pH}$ range for the coagulation process. However, the coagulation process is only effective in removing large organic precursors, so the conventional treatment methods have limited efficiency in eliminating small precursors, which have high formation potential of DBP (Chang et al. 2001a,b). 
Table 1. Total Organic Carbon Percent Removal Requirements for Enhanced Coagulation (Unit: \%)

\begin{tabular}{lccc}
\hline & \multicolumn{3}{c}{ Source water alkalinity $\left(\mathrm{mg} / \mathrm{L}\right.$ as $\left.\mathrm{CaCO}_{3}\right)$} \\
\cline { 2 - 4 } Total organic carbon $(\mathrm{mg} / \mathrm{L})$ & $0-60$ & $>60-120$ & $>120$ \\
\hline$>2.0-4.0$ & 40 & 30 & 20 \\
$>4.0-8.0$ & 45 & 35 & 25 \\
$>8.0$ & 50 & 40 & 30 \\
\hline
\end{tabular}

NOM concentrations in the source water of the King-Men Reservoir, Taiwan, are high and can not be easily reduced by the conventional-treatment process. For instance, TOC could only be reduced by $40 \%$ in the lime-coagulation process, resulting in the generation of high trihalomethane (THM) after chlorination. The purpose of this study was to evaluate NOM removal from source water by enhanced coagulation and activated carbon adsorption. The specific objectives were to (1) examine the characteristics of source water at the King-Men Reservoir; (2) assess the effect of polyaluminum chloride $(\mathrm{PACl})$ and alum dosages, as well as $\mathrm{pH}$, on NOM and turbidity removal; and (3) evaluate the effectiveness of activated carbon adsorption for reducing DBP precursors.

\section{Materials and Methods}

\section{Characterization of Source Water}

The source water from the King-Men Reservoir was collected from October 1998 to September 2000 for determining its molecular weight of NOM. NOM was fractionated by the UF membrane (A/G Technology), hollow-fiber modules with nominal molecular weight cut-off $1,5,10$, and 30 kilodaltons $(\mathrm{kDa})$. Each membrane was composed of cellulose derivative with a surface area of $24 \mathrm{~cm}^{2}$. The applied pressure through the membrane ranged from $270-350 \mathrm{kPa}$, and the filtrate was collected and analyzed for DOC and DBPFP (Thurman and Malcolm 1981).

\section{Coagulation Tests Performed by Alum and PACI}

A jar test was used to evaluate the reduction of NOM and THM by alum and $\mathrm{PACl}$. Reagent-grade alum $\left[\mathrm{Al}_{2}\left(\mathrm{SO}_{4}\right) \cdot 18 \mathrm{H}_{2} \mathrm{O}\right]\left(15 \% \mathrm{Al}_{2} \mathrm{O}_{3}\right)$ and $\mathrm{PACl}\left(10 \% \mathrm{Al}_{2} \mathrm{O}_{3}\right)$ were added at $20-130 \mathrm{mg} / \mathrm{L}$ and $30-450 \mathrm{mg} / \mathrm{L}$, respectively. Water samples were stirred by conventional jar-test apparatus with rapid mixing at $100 \mathrm{rpm}$ for $2 \mathrm{~min}$, slow mixing at $30 \mathrm{rpm}$ for $15 \mathrm{~min}$, and quiescent settling for $60 \mathrm{~min} . \mathrm{H}_{2} \mathrm{SO}_{4}$ was used for $\mathrm{pH}$ adjustment to evaluate the coagulation performance. At the end of the coagulation/settling period, $600 \mathrm{~mL}$ of the supernatant from the jar was collected and analyzed for TOC, turbidity, trihalomethane formation potential (THMFP) and haloacetic acid formation potential (HAAFP). Coagulated aliquots were filtered through prewashed $0.45 \mu \mathrm{m}$ filter to determine $\mathrm{UV}_{254}$ and DOC. In addition, the filtered samples were also prepared to perform the adsorption isotherm studies and determine the potential to form THM and haloacetic acid (HAA).

\section{Adsorption Isotherm Studies}

At first, the source-water sample was coagulated with $40 \mathrm{mg} / \mathrm{L}$ alum $(\mathrm{pH} \sim 6)$. At the end of the coagulation/settling period, the supernatant was filtered for activated carbon-adsorption studies. The Darco 20-40 mesh GAC (Aldrich) was first pretreated by boiling it with distilled water for several hours, then subsequently rinsed with distilled water, and finally dried in an electric oven at $120^{\circ} \mathrm{C}$ overnight. Adsorption isotherm experiments including a wide range of adsorbent/adsorbate ratio (0.6-2.4 $\mathrm{g}$ carbon/ $4.5 \mathrm{mg}$ DOC) were conducted at $22 \pm 2^{\circ} \mathrm{C}$. The equilibrium time was designated as $24 \mathrm{~h}$ throughout the entire adsorption isotherm tests. The carbon particles were separated from the liquid phase by centrifugation. Samples from the aqueous phase were analyzed for residual TOC concentration and DBP formation.

\section{Trihalomethanes and Haloacetic Acids Formation}

The appropriate chlorine doses of a water sample were determined from $3.5-20.0 \mathrm{mg} \mathrm{Cl}_{2} / \mathrm{L}$ based on the amount of free residual chlorine (APHA 1995). In general, the free residual chlorine was controlled in the range of $1.1-3.5 \mathrm{mg} / \mathrm{L}$ after at $20 \pm 2^{\circ} \mathrm{C}$. If the free residual chlorine was lower than $1 \mathrm{mg} / \mathrm{L}$, an additional amount, typically $3.5-20.0 \mathrm{mg} \mathrm{Cl}_{2} / \mathrm{L}$, was added to establish a definite residual. For the THM and HAA analysis, samples were collected at 6,24 , and $168 \mathrm{~h}$, respectively, after chlorine addition. The reason for sampling at $6 \mathrm{~h}$ was to determine the instantaneous THM (HAA) and THMFP (HAAFP), respectively, while a 24-h sampling time was arbitrarily selected for comparison with the DBP formation with respect to $168 \mathrm{~h}$. The $\mathrm{pH}$ value of the water samples was controlled by adding $5 \mathrm{~mL}$ phosphate buffer solution throughout these chlorination experiments. These treated samples were immediately sealed with a TFE-lined screw cap and then stored in the dark room. THMs were analyzed by high-pressure (HP) 6890 gas chromatography (GC)/ED. A microextraction procedure using methyl-tert-butyl ether [high-pressure liquid chromatography (HPLC) grade, Baker] and esterified with diazomethane, which was prepared in the laboratory following the procedures suggested by standard methods (APHA 1995), used to analyze HAA by the same GC. Standard solutions (Supelco) were prepared for calibrating four THM compounds (Cat. No. 48140-U) and five HAA compounds (Cat. No. 48047). In this research, according to the U.S. EPA's Stage 1 DBPR, five species of HAAs were taken into consideration (monobromoacetic acid (MBAA); dichloroacetic acid (DCAA); trichloroacetic acid (TCAA); bromochloroacetic acid (BCAA); and dibromoacetic acid (DBAA)). All the detailed quality assurance/quality control (QA/QC) requirements including detection limits, internal standard, surrogate standard, and preservative agents for DBP followed the procedures suggested by the standard methods (APHA 1995).

\section{Analytical Methods}

DOC, TOC, chlorine demand, DBPFP, $\mathrm{UV}_{254}$, turbidity, $\mathrm{pH}$, and alkalinity analyses were measured in raw-water and treated-water samples. All analyses, unless otherwise noted, were performed according to the 19th edition of the standard methods (APHA 1995). Water samples for DOC and $\mathrm{UV}_{254}$ analyses were first filtered through a prewashed $0.45 \mu \mathrm{m}$ filter and then determined by a TOC instrument (O. I. Corporation model 700) and UV spectroscopy (Hitachi U-2000), respectively.

\section{Results and Discussion}

\section{Characterization of Raw Water}

Table 2 presents the results of source-water analyses at the KingMen Reservoir, indicating a high TOC $(>8 \mathrm{mg} / \mathrm{L})$ and low alka- 


\begin{tabular}{|c|c|c|c|c|}
\hline \multirow[b]{2}{*}{ Parameters } & \multicolumn{3}{|c|}{ Concentration } & \multirow[b]{2}{*}{ Sample numbers } \\
\hline & Average & Range & Standard deviation & \\
\hline $\mathrm{pH}$ & Not available & $6.5-7.5$ & Not available & 7 \\
\hline Alkalinity—mg/L as $\mathrm{CaCO}_{3}$ & 52.6 & $36.6-71.8$ & 17.8 & 7 \\
\hline Turbidity-NTU & 14.0 & $7.7-25.0$ & 6.4 & 7 \\
\hline $\mathrm{UV}_{254}$ & 0.158 & $0.108-0.218$ & 0.042 & 7 \\
\hline Total organic carbon-mg/L & 9.6 & $7.0-12.4$ & 1.9 & 7 \\
\hline \multicolumn{5}{|l|}{ Chlorine demand $-\mathrm{mg} / \mathrm{L}$ as $\mathrm{Cl}_{2}$} \\
\hline $6 \mathrm{~h}$ & 11.3 & $6.1-18.5$ & 4.8 & 7 \\
\hline $24 \mathrm{~h}$ & 12.6 & $6.4-21.2$ & 5.7 & 7 \\
\hline $168 \mathrm{~h}$ & 35.5 & $17.0-68.7$ & 21.9 & 7 \\
\hline \multicolumn{5}{|l|}{ THM formation potential- $\mu \mathrm{g} / \mathrm{L}$} \\
\hline $6 \mathrm{~h}$ & 186 & $118-226$ & 41 & 6 \\
\hline $24 \mathrm{~h}$ & 361 & $168-487$ & 109 & 6 \\
\hline $168 \mathrm{~h}$ & 703 & $367-1,427$ & 344 & 7 \\
\hline \multicolumn{5}{|l|}{ HAA formation potential $-\mu \mathrm{g} / \mathrm{L}$} \\
\hline $168 \mathrm{~h}$ & 471 & $236-655$ & 156 & 7 \\
\hline \multicolumn{5}{|l|}{ Molecular size- $\%$} \\
\hline$>1 \mathrm{k}$ & 41 & $33-47$ & 7 & 3 \\
\hline $1 \mathrm{k} \sim 5 \mathrm{k}$ & 11 & $6-18$ & 6 & 3 \\
\hline $5 \mathrm{k} \sim 10 \mathrm{k}$ & 5 & $2-7$ & 3 & 3 \\
\hline $10 \mathrm{k} \sim 30 \mathrm{k}$ & 1 & $1-2$ & 1 & 3 \\
\hline$>30 \mathrm{k}$ & 42 & $32-57$ & 13 & 3 \\
\hline
\end{tabular}

linity ( $<60 \mathrm{mg} / \mathrm{L}$ as $\mathrm{CaCO}_{3}$ ). This source water has the dominant DOC distribution with MW less than $1 \mathrm{kDa}(41 \%)$ and greater than $30 \mathrm{kDa}(42 \%)$. Previous studies (Chiang et al. 2002) reported that MW distributions of reservoir-water samples were relatively even. These results are quite different from other studies (Amy et al. 1992; Newcombe et al. 1997), which suggests that the MW characteristics are site specific. The MW fraction affecting the performance of different treatment processes is discussed later.

In addition, the percentages of THMs and HAAs at various MW ranges of organic matter of the source water are shown in Fig. 1. It is clear that King-Men source water contains higher concentrations of DOC in the MW fractions $>30 \mathrm{kDa}$ and $<1$ $\mathrm{kDa}$. Accordingly, the highest distributions of four species of THMs are in the MW fractions $>30 \mathrm{kDa}$, and the ratios range from $46-67 \%$. On the other hand, the same as the distribution of THMs precursor, the HAAs precursor distributions of the source water constitute most of MW organics $>30 \mathrm{kDa}(55 \%)$ and $<1$ $\mathrm{kDa}(40 \%)$. Thus, removal of these two major fractions in watertreatment processes is the key to reduce the level of DBPs in the treated water.

In Table 2, it is also observed that the THM and HAA concentrations in the finished water at the King-Men water-treatment plant may not meet the future stringent drinking-water standards, i.e., 80 and $60 \mu \mathrm{g} / \mathrm{L}$, respectively. Consequently, an alternative treatment method of ozonation, enhanced coagulation, adsorption, and/or nanofiltration would be required for reducing NOM. In this investigation, there were only two unit processes, coagulation and adsorption, selected for further evaluation.

The U.S. EPA proposed the following equation for modeling the concentration of THM in the course of drinking-water disinfection (Singer 1994):

$$
\begin{aligned}
\text { TTHM }= & 0.00309[(\text { TOC })(\mathrm{UV}-254)]^{0.440} \\
& \times\left(\mathrm{Cl}_{2}\right)^{0.409}(t)^{0.265}(T)^{1.06}(\mathrm{pH}-2.6)^{0.715} \times(\mathrm{Br}+1)^{0.036}
\end{aligned}
$$

where $\mathrm{TTHM}=$ total trihalomethane concentration $(\mu \mathrm{mol} / \mathrm{L})$; $t=$ time $(\mathrm{h}) ; T=$ temperature $\left({ }^{\circ} \mathrm{C}\right) ; \mathrm{Br}=$ bromide ion concentration $(\mathrm{mg} / \mathrm{L})$; and $\mathrm{Cl}_{2}=$ chlorine dose $(\mathrm{mg} / \mathrm{L})$. In Eq. (1) the $\mathrm{pH}$ index, $\mathrm{pH}-2.6$, can be regarded as an important factor affecting THM formation. However, this index can be varied with the characterization of NOM in the different location. This hypothesis is also clearly demonstrated in Fig. 2, which indicates the $\mathrm{pH}$ index appears as $\mathrm{pH}-3.7$, a proportional factor indicating its effect on the formation of THMs and HAAs.
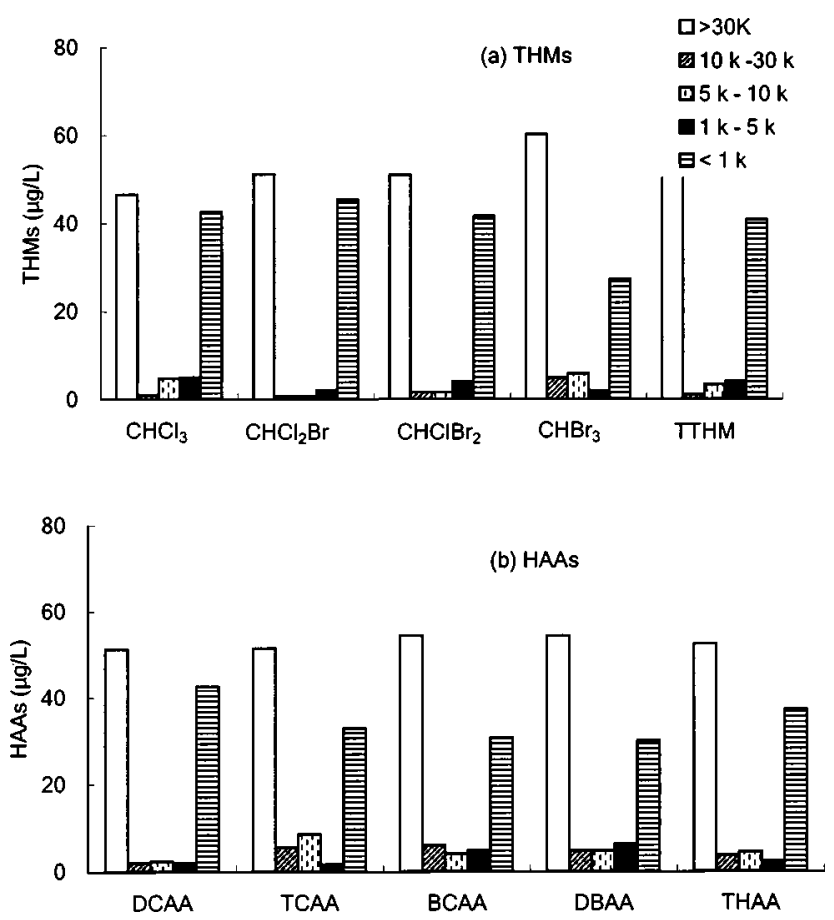

Fig. 1. Molecular weight characteristics for source water (a) THMs and (b) HAAs. 


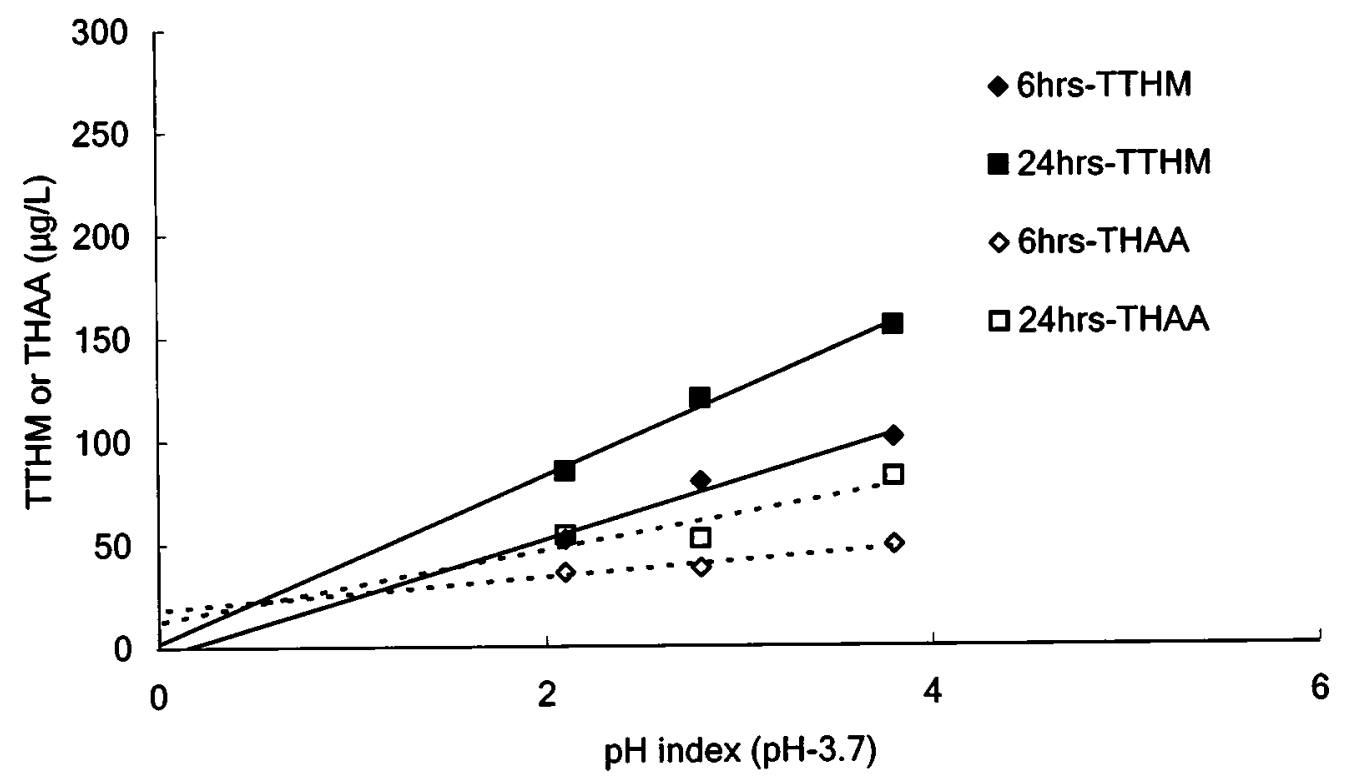

Fig. 2. Results of correlation between $\mathrm{pH}$ index

\section{Reduction of Natural Organic Matter and Disinfection By-Products by Coagulation}

An alum dose of $20 \mathrm{mg} / \mathrm{L}$ reduced the TOC concentration by $25 \%$, as shown in Fig. 3. As the alum dosage increased further, the reduction in TOC and turbidity also increased gradually. As suggested by the U.S. EPA (1998), an alum dose of approximately $40 \mathrm{mg} / \mathrm{L}$ should be introduced to meet the Step 1 TOC removal requirement $(50 \%)$ for this high-TOC and low-alkalinity water. For the present study, a $40 \mathrm{mg} / \mathrm{L}$ alum dosage decreased turbidity to below 2 NTU and was at the point of diminishing returns for TOC reduction. For example, as alum dosage increased from 60-90 mg/L, the difference in TOC removal efficiency was found to be insignificant $(0.23 \mathrm{mg}$ TOC/10 mg alum) even operating in the lower $\mathrm{pH}$ range (5.8), which is fairly consistent with the findings suggested by the U.S. EPA enhanced coagulation requirement. On the other hand, it is noted that restabilization may have occurred, thereby increasing the residual TOC and turbidity at the PACl dosage $450 \mathrm{mg} / \mathrm{L}$ at $10 \% \mathrm{Al}_{2} \mathrm{O}_{3}$ [Fig. 3(b)]. This hypothesis could be further confirmed by the evidences shown later in Figs. 5(b) and 6(b), which exhibit relatively lower removal efficiencies at the PACl dosage $450 \mathrm{mg} / \mathrm{L}$.

It is believed that the coagulation process had poor capability to eliminate small MW organics, which occupies the second high fractions of organic matters and DBP precursors in King-Men source water (Table 2 and Fig. 1). This observation is also consistent with our previous study evaluating the performance of a full-scale coagulation process, which indicated that the coagulation is able to remove large MW fractions $(>30 \mathrm{kDa})$ with about $59 \%$ DOC reduction, as compared to $7 \%$ elimination for the MW fraction $<1 \mathrm{kDa}$. (Chiang et al. 2002). Due to the characteristics of the source-water nature, the coagulation process has its limitation to reduce organics efficiently even at high-coagulant dose.

In Figs. 4 and 5, it is observed that $\mathrm{CHCl}_{3}$ and $\mathrm{CHBrCl}_{2}$ decrease rapidly at $60 \mathrm{mg} / \mathrm{L}$ dose (alum and $\mathrm{PACl}$ ) and then decrease gradually with increased chemical dosage. Small quantities of $\mathrm{CHBr}_{2} \mathrm{Cl}$, however, do not change significantly. Observationally, $\mathrm{CHCl}_{3}$ is the predominant species in the total THM formation due to the nature of the chlorination process as well as water characteristics, e.g., the incorporation factor and $\mathrm{Cl}_{2} / \mathrm{Br}^{-}$molar ratio (Chang et al. 2001a,b).
Fig. 6 presents the 6 -h results of HAA formation in water samples treated by alum and PACl. TCAA is the major component of HAA. The patterns of the five HAA species at different levels of alum and PACl are as follows: (1) TCAA concentrations decreased gradually with increased chemical dosage; (2) MBAA and DCAA declined significantly; (3) BCAA decreased initially
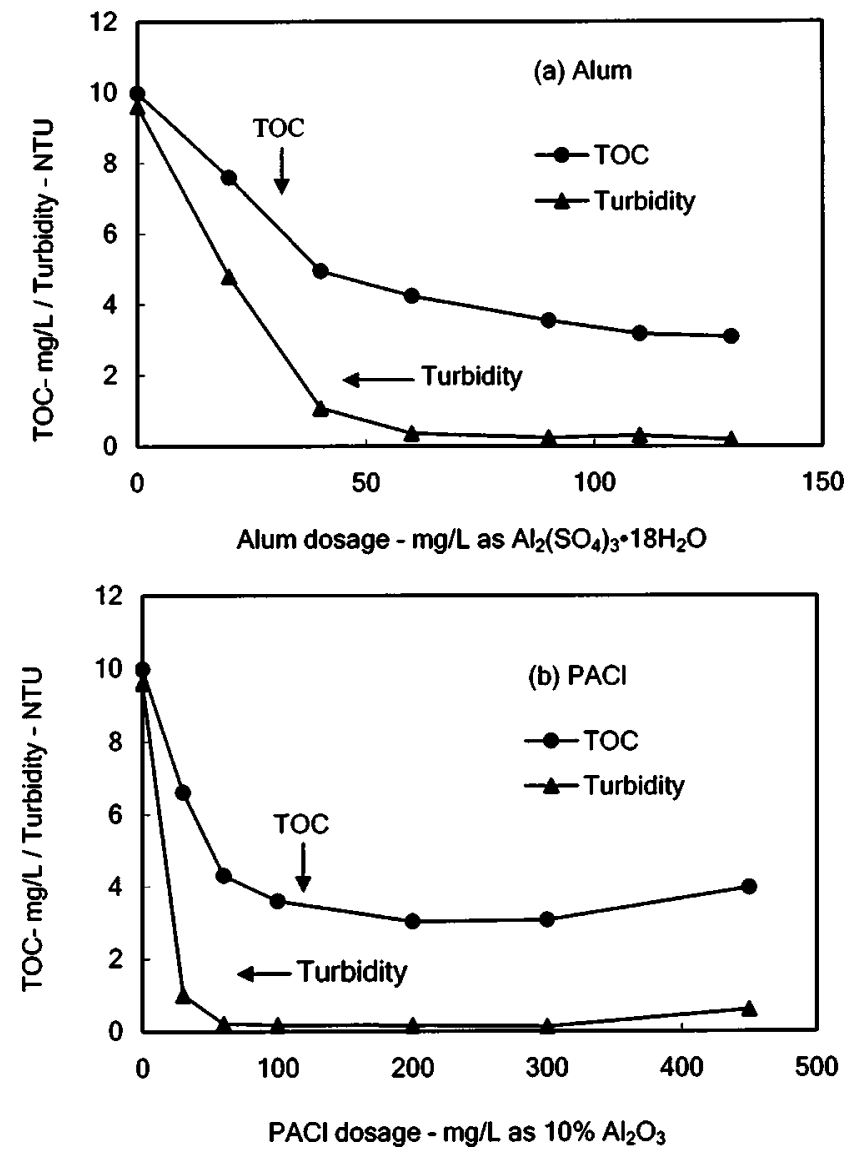

Fig. 3. Residual total organic carbon (TOC) and turbidity levels treated by various levels of (a) alum and (b) PACl coagulant dose 

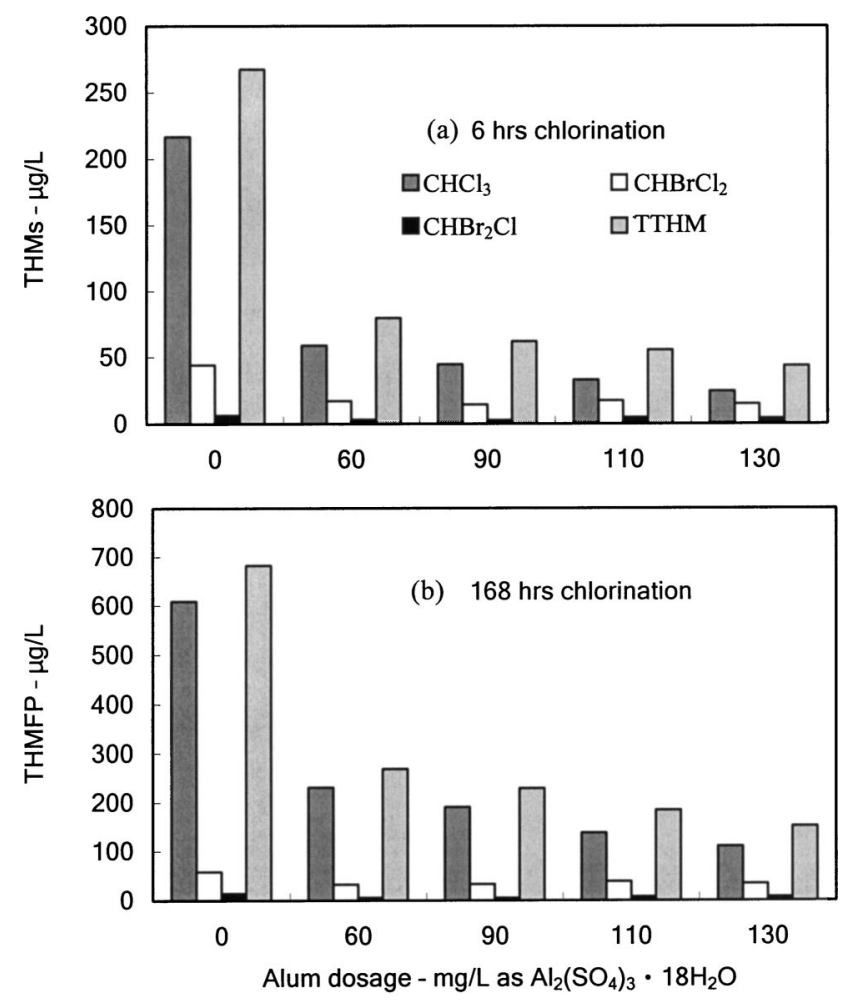

Fig. 4. (a) THMs and (b) THMFP in source water treated by alum

and then increased slowly in the alum coagulation case; and (4) DBAA did not change appreciably. In general, the alum and $\mathrm{PACl}$ coagulants can be successfully used in reducing HAA precursors except for the occurrence of restabilization at higher PACl dosages.

Figs. 7 and 8 show the THM and HAA formation in water samples treated by various levels of alum and $\mathrm{PACl}$, respectively. For comparison purposes, chemical dosages are expressed as $\mathrm{Al}_{2} \mathrm{O}_{3}$. The organic precursors in the source water were reduced significantly by alum at doses higher than $10 \mathrm{mg} / \mathrm{L}$ as $\mathrm{Al}_{2} \mathrm{O}_{3}$, under which the residual turbidity was below 1 NTU. The TTHM and the total haloacetic acids (THAA) concentrations in the source water treated by $\mathrm{PACl}$ also decreased gradually up to 30 $\mathrm{mg} / \mathrm{L}$ as $\mathrm{Al}_{2} \mathrm{O}_{3}$. However, as the $\mathrm{PACl}$ dosage increased to 45 $\mathrm{mg} / \mathrm{L}$ as $\mathrm{Al}_{2} \mathrm{O}_{3}$, slightly increased concentrations of TTHM and THAA in the treated water are observed as was TOC [Fig. 3(b)]. TTHM (THAA) approached a level equivalent to $40 \%(30 \%)$ of DBPFP after $6 \mathrm{~h}$ of contact time. It is also noted that the TTHM concentration was higher than $80 \mu \mathrm{g} / \mathrm{L}$, i.e., the future drinkingwater-quality standard in Taiwan, even though the residual turbidity was controlled below $0.3 \mathrm{NTU}$ by using the enhanced coagulation technique $\left(110 \mathrm{mg} / \mathrm{L}\right.$ alum or $16.5 \mathrm{mg} / \mathrm{L}$ alum as $\left.\mathrm{Al}_{2} \mathrm{O}_{3}\right)$. In comparison with the performance between alum and $\mathrm{PACl}$ (Fig. $3)$, a lower dose $\left(60 \mathrm{mg} / \mathrm{L}\right.$ as $\left.10 \% \mathrm{Al}_{2} \mathrm{O}_{3}\right)$ of $\mathrm{PACl}$ coagulant is more effective in removing TOC and turbidity than the same dose of alum. The results show that the larger MW coagulant (PACl), having a higher-charge neutralization and bridging capacities, exhibits better performance than the lower MW alum. However, the benefit of using $\mathrm{PACl}$ chemical was intangible at a higher dosage of coagulant.

In addition, $\mathrm{pH}$ in the source water would be changed during the coagulation process. For instance, the $\mathrm{pH}$ value decreases from 7.0-5.8 after the coagulation process. It is necessary to readjust the $\mathrm{pH}$ value in the finished water to meet the drinkingwater standard in Taiwan. Furthermore, the THMFP varied with
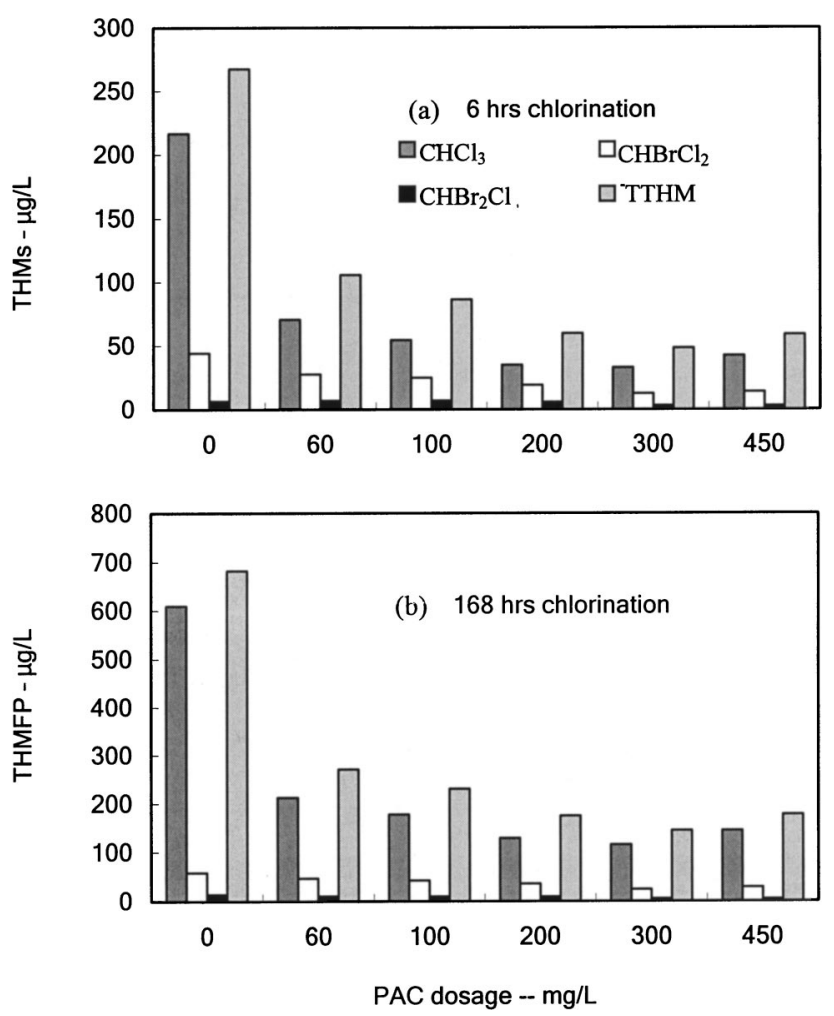

Fig. 5. (a) THMs and (b) THMFP in source water treated by PACl
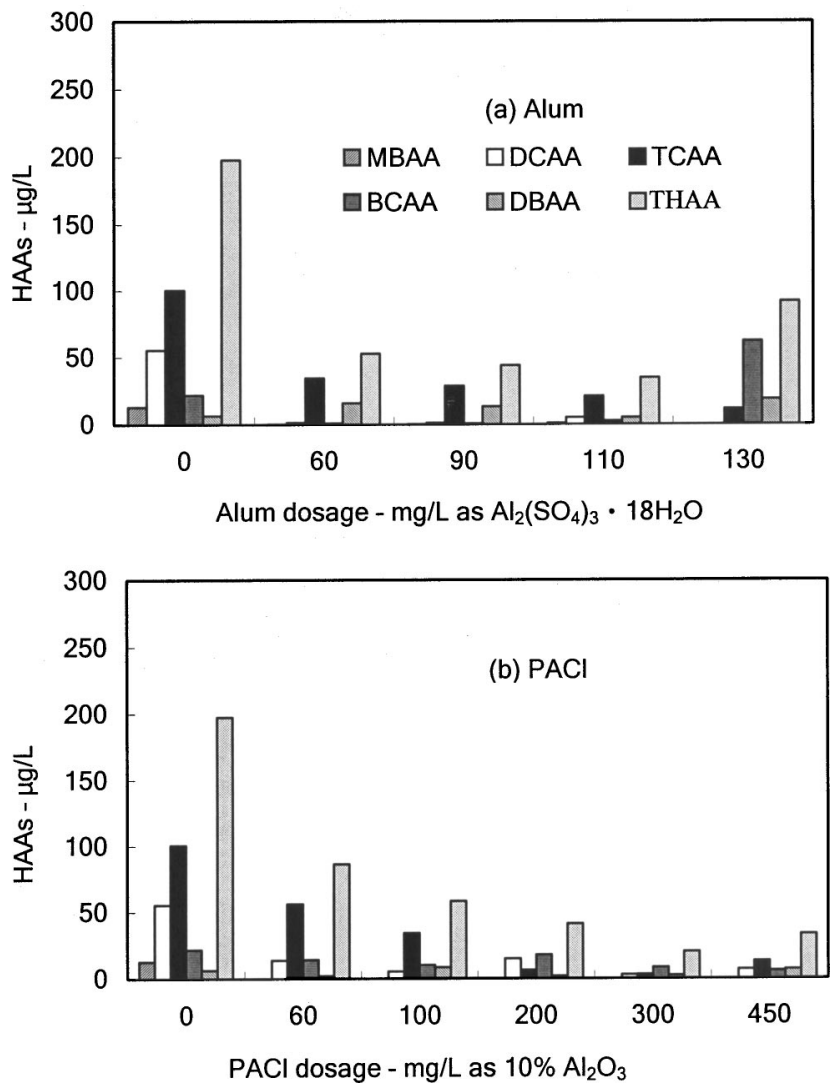

Fig. 6. HAA formation $(6 \mathrm{~h})$ in source water treated by (a) alum and (b) $\mathrm{PACl}$ 

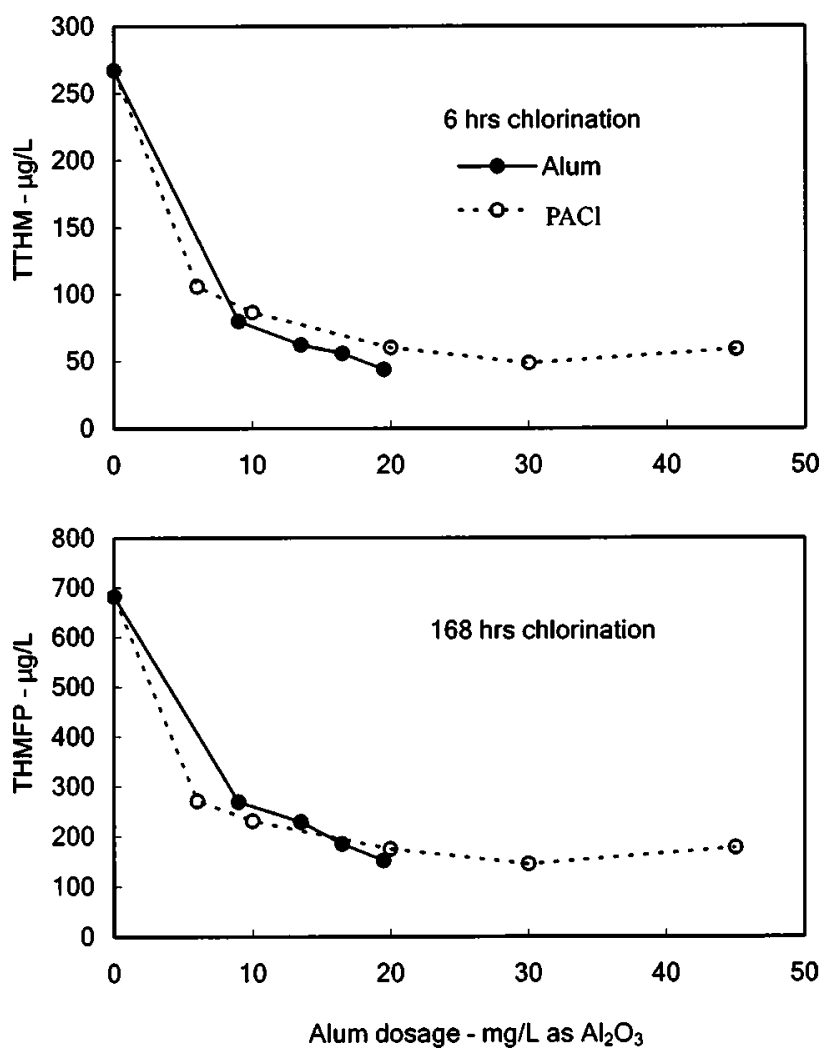

Fig. 7. Comparisons of TTHM and THMFP between alum and PACl

different acidic or alkaline conditions of the finished water as shown in Fig. 9. For HAA, it is observed that the $\mathrm{pH}$ at 5.8 and 6.5 did not make a significant difference in the formation of HAA. However, the $\mathrm{pH}$ value at 7.5 did increase $20-40 \%$ of the HAA formation as compared with the $\mathrm{pH}$ value at 6.5 . The effect of $\mathrm{pH}$ on the formation of THM is more noticeable than on that of HAA, e.g., the measured TTHM concentrations $(6 \mathrm{~h})$ at $\mathrm{pH} 6.5$ and 7.5 are 84 and $104 \mu \mathrm{g} / \mathrm{L}$, respectively, which are higher than the drinking-water standard. This observation provides additional evidence that the treated water by $\mathrm{PACl}$ or alum coagulant might promote higher DBP formation if the final $\mathrm{pH}$ adjustment is needed.

\section{Reduction of Natural Organic Matter and Disinfection By-Product by Adsorption}

Some researchers have indicated that coagulation with alum is effective for the removal of organic DBP precursors (Babcock and Singer 1979; White et al. 1997). On the contrary, Crozes et al. (1995) suggested that the anticipated maximum contaminant levels for HAA and THM could hardly be met by using enhanced coagulation. Recently Singer and Bilyk (2002) used alum combined with an ion-exchange resin to remove organic matters and DBP precursors from natural waters, and indicated that the combination method was more effective as compared to alum coagulation alone despite the fact that lower alum doses were used. This result implies that the precursors of THMs and HAAs are better reduced by other mechanisms such as adsorption; hence GAC was introduced to reinforce alum or $\mathrm{PACl}$ treatment.

NOM is adsorbed by activated carbon depending on conditions such as $\mathrm{pH}$ and DOC concentration. Lower $\mathrm{pH}$ reduces the charge density of humic and fulvic acids making them more hydrophobic (Krasner and Amy 1995). In general, activated carbon
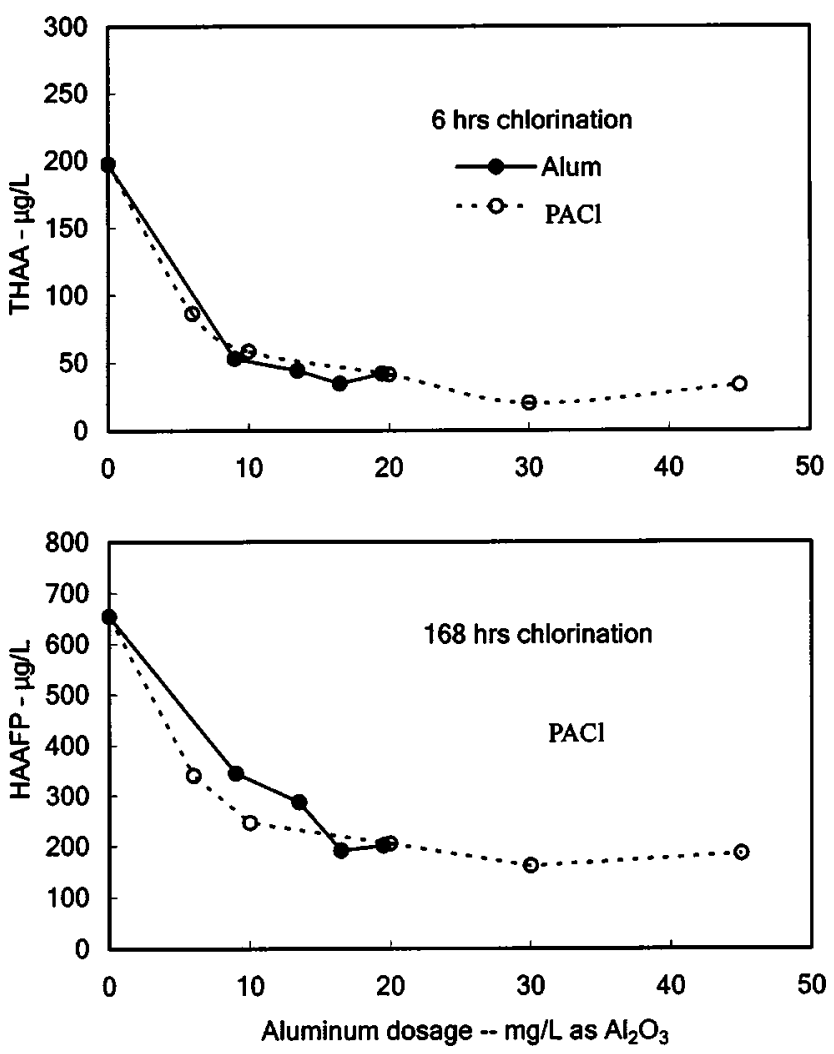

Fig. 8. Comparisons of THAA and HAAFP between alum and PACl

display has a higher adsorption capacity at a lower $\mathrm{pH}$, which can be ascribed to the decrease in surface NOM electrostatic repulsions, as well as to the decrease in the solubility and in the size of the NOM molecule at $\mathrm{pH} 3$ (Newcombe 1999). In addition, our colleague reported that TOC removal by adsorption increased about $10 \%$ and $30 \%$ as the $\mathrm{pH}$ was reduced from 8.0-6.0, and 2.0 , respectively. It was noted that the $\mathrm{pH}$ reduction prior to GAC adsorption might be beneficial for a water-treatment unit, but the cost of $\mathrm{pH}$ control for adding acid to reduce the $\mathrm{pH}$ and adding alkali to restore a stable $\mathrm{pH}$ and following a GAC unit is debatable. (Chen 1996) Consequently, the adsorption-isotherm experiments in this investigation were conducted at $\mathrm{pH} 5.8-7.5$ after the coagulation tests.

Because a large MW fraction of NOM can cause pore blockage of activated carbon and result in the decrease of effective

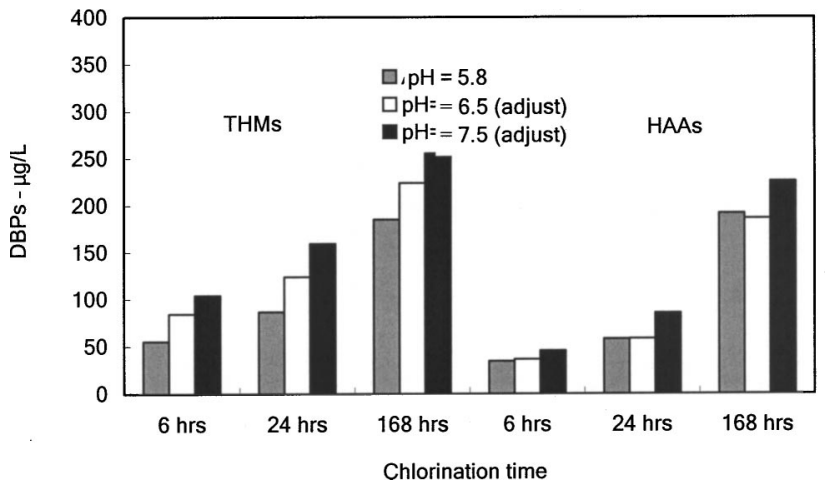

Fig. 9. Disinfection by-product (DBP) formation of source water treated by alum at different levels of $\mathrm{pH}$ 


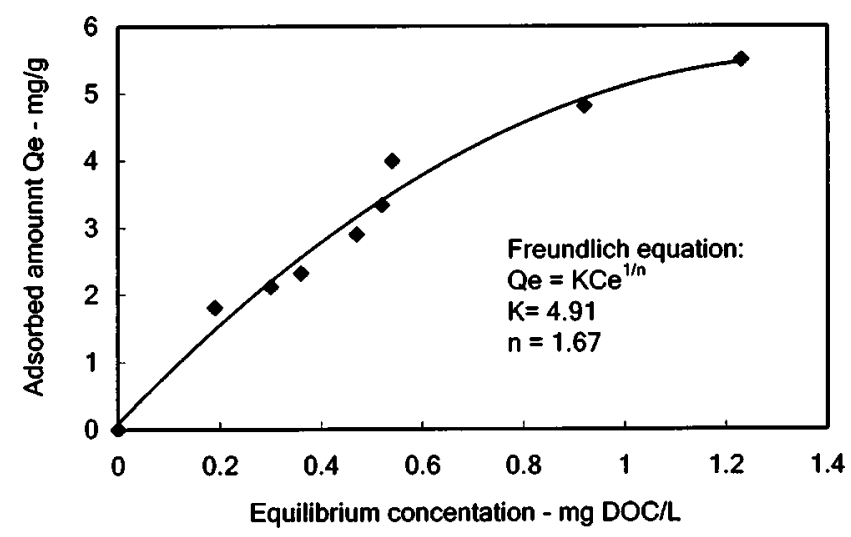

Fig. 10. Adsorption isotherm of dissolved organic compound (DOC) on Darco (Aldrich) activated carbon (initial DOC $=4.5 \mathrm{mg} / \mathrm{L}$ )

adsorption sites (Pelekani and Snoeyink 1999; Ebie et al. 2001), the coagulation preceding the GAC process can prevent the GAC from pore blockage by large MW organics. Furthermore, the remaining small MW organics after coagulation/sedimentation processes can be expected to be removed by GAC adsorption. Fig. 10 presents the results of Darco carbon-adsorption isotherm studies, indicating that a favorable adsorption results in an effective reduction of DBP precursors. The Freundlich isotherm reasonably predicts the observed values. The plots in Fig. 11 reaffirm the fact that THM and HAA are greatly reduced with increased GAC dosage. For instance, the measured DBP were found to be below $20 \mu \mathrm{g} / \mathrm{L}$ at GAC $1.0 \mathrm{~g} / \mathrm{L}$.

\section{Conclusion}

The characterization of NOM in the King-Men source water has the dominant TOC distribution with MW less than $1 \mathrm{kDa}(41 \%)$ and greater than $30 \mathrm{kDa}(42 \%)$. Accordingly, the highest distributions of THMs and HAAs are in the MW fractions $>30 \mathrm{kDa}$ and $<1 \mathrm{kDa}$. With this every unique characterization, a lower alum dosage could reduce the TOC concentration by a great amount (25\%); while at a higher dosage (60-90 $\mathrm{mg} / \mathrm{L})$, the difference in TOC removal efficiency was found to be insignificant $(0.23 \mathrm{mg}$ $\mathrm{TOC} / 10 \mathrm{mg}$ alum), even operating in a lower $\mathrm{pH}$ range. This is probably due to the characteristics of the source-water nature, the coagulation process has its limitation to reduce organics efficiently even at a high-coagulant dose. With the PACl dosage at a higher level, restabilization occurred, resulting in higher TOC and THM concentrations in the treated water.

In comparison with the performance between alum and $\mathrm{PACl}$, a lower dose of $\mathrm{PACl}$ coagulant is more effective in removing TOC and turbidity than the same dose of alum. The results show that the larger MW coagulant (PACl), having a higher-charge neutralization and bridging capacities, exhibits better performance than the lower MW alum. However, the benefit of using a $\mathrm{PACl}$ chemical was intangible at a higher dosage of coagulant. It was also observed that the $\mathrm{pH}$ at 5.8 and 6.5 did not significantly affect the formation of HAA, while a $\mathrm{pH}$ of 7.5 did increase the HAA formation by $20-40 \%$. The results further demonstrate that the treated water by $\mathrm{PACl}$ or alum coagulant might promote higher DBP formation if the final $\mathrm{pH}$ adjustment is needed.

The GAC adsorption process provides a relatively lower THMFP in the treated water at the same level of THM and in addition to lower the coagulant doses demand. In addition, the
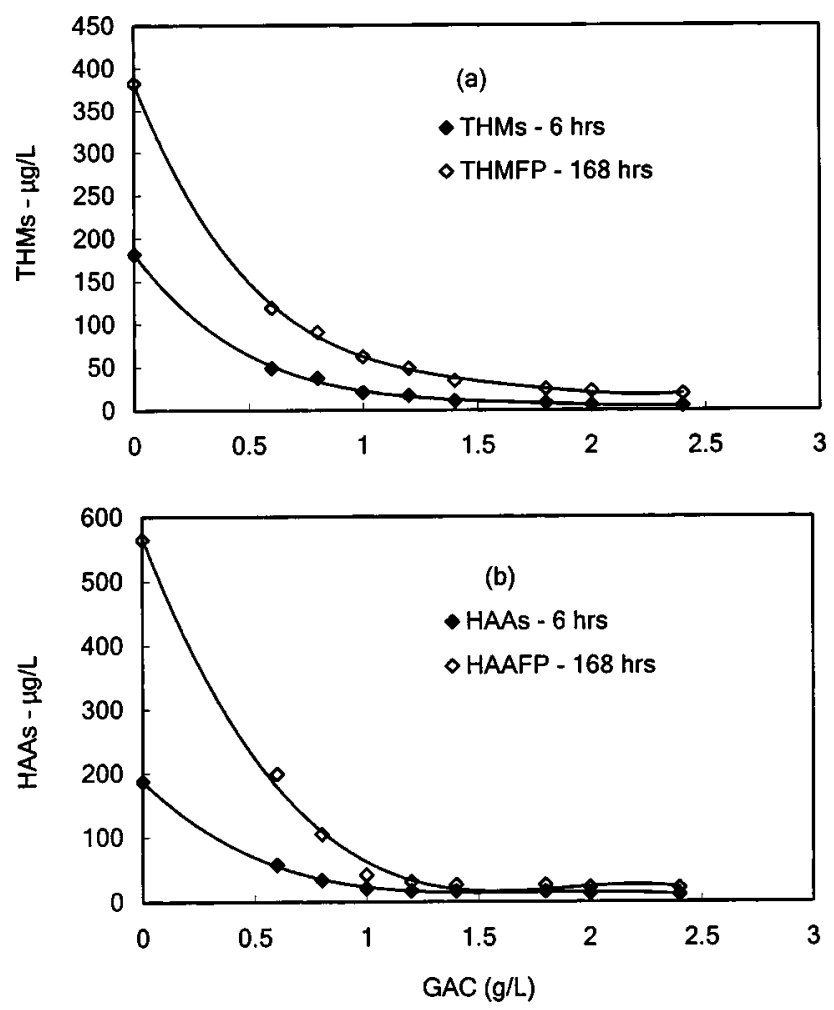

Fig. 11. Disinfected by-product formation treated by various levels of GAC (a) THMs and (b) HAAs

GAC process can effectively remove small MW organics which is difficult to remove by the coagulation process. Thus, the water treated by the alum coagulation followed by adsorption process should provide safer drinking-water quality with regard to DBP formation, and the removal mechanisms should be described quantitatively in future work.

\section{References}

American Public Health Association (APHA). (1995). Standard methods for the examination of water and wastewater, 19th Ed., Washington, D.C.

Amy, G. L., Siwrka, R. A., Bedessem, J., Price, D., and Tan, L. (1992). "Molecular size distributions of dissolved organic matter." J. Am. Water Works Assoc., 84(6), 67-75.

Babcock, D. S., and Singer, P. C. (1979). "Chlorination and coagulation of humic and fulvic acids." J. Am. Water Works Assoc., 71(3), 149152.

Chadik, P. A., and Amy, G. L. (1983). "Removing trihalomethane precursors from various natural water by metal coagulants." J. Am. Water Works Assoc., 75(10), 532-536.

Chang, E. E., Chiang, P. C., Ko, Y. W., and Lan, W. H. (2001a). "Effects of bromide on the formation of THMs and HAAs." Chemosphere, 44(5), 1231-1236.

Chang, E. E., Lin, Y. P., and Chiang, P. C. (2001b). "Effects of bromide on the formation of THMs and HAAs." Chemosphere, 43(8), 10291034.

Chen, H. L., Jeng, H. J., and Chen, K. M. (1996). "Evaluation of granular activated carbon for removal of trace organic compounds in drinking water." Environ. Int., 22(3), 343-359.

Chiang, P. C., Chang, E. E., and Liang, C. H. (2002). "NOM characteristics and the treatabilities of ozonation processes." Chemosphere, 46(6), 929-936. 
Crozes, G., White, P., and Marshall, M. (1995). "Enhanced coagulation: Its effect on NOM removal and chemical costs." J. Am. Water Works Assoc., 87(1), 78-89.

Ebie, K., Li, F., Azuma, Y., Yuasa, A., and Hagishita, T. (2001). "Pore distribution effect of activated carbon in adsorbing organic micropollutants from natural water." Water Res., 35(1), 167-179.

Edzwald, J. K. (1993). "Coagulation in drinking water treatment: Particles, organics, and coagulants." Water Sci. Technol., 27(11), 21-35.

Edzwald, J. K., Becker, W. C., and Wattier, K. L. (1985). "Surrogate parameters for monitoring organic matter and THM precursors." $J$. Am. Water Works Assoc., 77(4), 122-131.

Hubel, R. E., and Edzwald, J. K. (1987). "Removing trihalomethane precursors by coagulation." J. Am. Water Works Assoc., 79(7), 98106.

Jacangelo, J. G., DeMarco, J., Owen, D. M., and Randtke, S. J. (1995). "Selected processes for removing NOM: An overview." J. Am. Water Works Assoc., 87(1), 64-77.

Kavanaugh, M. C. (1978). "Modified coagulation for improved removal of trihalomethane precursors." J. Am. Water Works Assoc., 70(11), 613-620.

Krasner, S. W., and Amy, G. L. (1995). "Jar-test evaluations of enhanced coagulation." J. Am. Water Works Assoc., 87(10), 93-107.

Najm, I., Marcinko, J., and Oppenheimer, J. (2000). "Evaluating TOC analytical results." J. Am. Water Works Assoc., 92(8), 84-92.

Najm, I. N., Patania, N. L., Jacangelo, J. G., and Krasner, S. W. (1994). "Evaluating surrogates for disinfection by-products." J. Am. Water Works Assoc., 86(6), 98-106.

Newcombe, G. (1999). "Charge vs. porosity—some influences on the adsorption of natural organic matter (NOM) by activated carbon." Water Sci. Technol., 40(9), 191-198.

Newcombe, G., Drikas, M., Assemi, A., and Beckett, R. (1997). "Influence of characterized natural organic material on activated carbon adsorption: I. Characterization of concentrated reservoir water." Water Res., 31(5), 965-972.

Owen, D. M., Amy, G. L., Chowdhury, Z. K., Paode, R., McCoy, G., and Viscosil, K. (1995). "NOM characterization and treatability." J. Am. Water Works Assoc., 87(1), 46-63.

Pelekani, C., and Snoeyink, Y. L. (1999). "Competitive adsorption in natural water: Role of activated carbon pore size." Water Res., 33(5), 1209-1219.

Reckhow, D. A., and Singer, P. C. (1984). "The removal of organic halide precursors by preozonation and alum coagulation." J. Am. Water Works Assoc., 76(4), 151-157.

Semmens, M. J., and Field, T. K. (1980). "Coagulation experiences in organics removal." J. Am. Water Works Assoc., 72(8), 476-483.

Singer, P. C. (1994). "Control of disinfection by-products in drinking water." J. Environ. Eng., (Reston, Va.) 120(4), 727-744.

Singer, P. C., and Bilyk, K. (2002). "Enhanced coagulation using an ion exchange resin." Water Res., 36(16), 4009-4022.

Thurman, E. M., and Malcolm, R. L. (1981). "Preparative isolation of aquatic humic substances." Environ. Sci. Technol., 15(4), 463-466.

U.S. EPA. (1998). "Disinfectants and disinfection byproducts: Final rule." Washington, D.C.

White, M. C., Thompson, J. D., Harrington, G. W., and Singer, P. C. (1997). "Evaluating criteria for enhanced coagulation compliance." $J$. Am. Water Works Assoc., 89(5), 64-77. 